Subscriber access provided by Universidad de Alicante

\title{
Article
}

\section{Revisiting the atomistic structures at the interface of Au(111) electrode-sulfuric acid solution}

Yuan Fang, Songyuan Ding, Meng Zhang, Stephan N. Steinmann, Ren Hu, Bingwei Mao, Juan Miguel Feliu, and Zhongqun Tian

J. Am. Chem. Soc., Just Accepted Manuscript • DOI: 10.1021/jacs.0c02639 • Publication Date (Web): 27 Apr 2020

Downloaded from pubs.acs.org on May 2, 2020

\section{Just Accepted}

"Just Accepted" manuscripts have been peer-reviewed and accepted for publication. They are posted online prior to technical editing, formatting for publication and author proofing. The American Chemical Society provides "Just Accepted" as a service to the research community to expedite the dissemination of scientific material as soon as possible after acceptance. "Just Accepted" manuscripts appear in full in PDF format accompanied by an HTML abstract. "Just Accepted" manuscripts have been fully peer reviewed, but should not be considered the official version of record. They are citable by the Digital Object Identifier (DOI®). "Just Accepted" is an optional service offered to authors. Therefore, the "Just Accepted" Web site may not include all articles that will be published in the journal. After a manuscript is technically edited and formatted, it will be removed from the "Just Accepted" Web site and published as an ASAP article. Note that technical editing may introduce minor changes to the manuscript text and/or graphics which could affect content, and all legal disclaimers and ethical guidelines that apply to the journal pertain. ACS cannot be held responsible for errors or consequences arising from the use of information contained in these "Just Accepted" manuscripts. 


\section{INTRODUCTION}

Solid/liquid interfacial structures play crucial roles in determining chemical processes, such as electrochemistry, catalysis, corrosion, composite formation, wear and wetting. ${ }^{1-3}$ At electrode/electrolyte solution interfaces, specifically adsorbed anions e.g., sulfate, superoxide, and halide anions and water solvent molecules can reconstruct the interfacial structures, and thus affect the thermodynamics and kinetics of electrode processes. ${ }^{4-6}$ It is of fundamental importance to probe the atomistic details of the electrochemical (EC) interfaces.

Adsorption of sulfate or bisulfate anions on the surface of an atomically flat $\mathrm{M}(111)$ electrodes $(\mathrm{M}=\mathrm{Au}, \mathrm{Pt}, \mathrm{Rh}, \mathrm{Cu}, \mathrm{Ir}$, and $\mathrm{Pd}$ ) in sulfuric acid are representative systems of electrosorption in interfacial electrochemistry and surface science. ${ }^{7-8}$ Specifically for $\mathrm{Au}(111)$, in 1984, Scherson et al. first observed a pair of sharp reversible current spikes at $\sim 1.06$ $\mathrm{V} v s$. SHE below the oxygen evolution potential in the cyclic voltammogram (CV) of $\mathrm{Au}(111)$ single-crystal electrodes in $\mathrm{H}_{2} \mathrm{SO}_{4}$ aqueous solutions, and attributed the spikes to a phase transition of the anion adlayer. ${ }^{9}$ Since then a series of in-situ electrochemical scanning tunneling microscopy (EC-STM) and electrochemical infrared (EC-IR) spectroscopy have been employed by more than ten distinguished groups in the field of interfacial electrochemistry and surface science to elucidate the detailed structure and process associated with the current spikes. In 1992, Magnussen et al. employed EC-STM to firstly observe a $(\sqrt{3} \times \sqrt{7})$ patterned adstructure near the sharp current spikes and proposed it to be composed of adsorbed bisulfate anions $\left(\mathrm{HSO}_{4}{ }^{*}\right.$, the charge of the electro-adsorbed species is usually fractional and depends on the applied potential; * denotes the adsorbed species). ${ }^{10}$ In 1994, the Weaver group assigned the possible adstructure as the sulfate anion coadsorbed with a hydronium cation $\mathrm{SO}_{4} \cdots \mathrm{H}_{3} \mathrm{O} *$ by performing 
the combined EC-STM and EC-IR method. ${ }^{11}$ The Osawa group interpreted the measured synchronous 2D EC-IR spectra on the ultra-flat $\mathrm{Au}$ film electrode as a sulfate anion coadsorbed with one water molecule (w) as $\mathrm{SO}_{4} \cdots \mathrm{w}^{*}$ with two possible hydrogen-bonding configurations. ${ }^{12}$ Several possible configurations have been proposed according to the empirical assignments of the bands observed in the EC-IR spectra and/or qualitative assignments of the fuzzy features in the EC-STM images. ${ }^{13-15}$ The Lipkowski and Wieckowski groups employed chronocoulometry and radiochemistry to deduce that the adstructure is $\mathrm{SO}_{4}{ }^{*}$ instead of $\mathrm{HSO}_{4} *{ }^{16}$ Theoretically, the Jacob group concluded that the configuration with $\mathrm{SO}_{4} \cdots \mathrm{H}_{3} \mathrm{O} *$ is the most stable configurations by calculating binding energies of eight possible configurations based on periodic density functional theory (DFT). ${ }^{17}$ However, the applied potential, and solvation effects were not considered in the calculation. In short, most groups supported that the main adsorbates are sulfate anions.

Although more than ten adsorption configurations for the $\mathrm{Au}(111) / \mathrm{H}_{2} \mathrm{SO}_{4}$ system have been proposed in the past four decades, the atomistic structure of the $\mathrm{Au}(111)(\sqrt{3} \times \sqrt{7})$ adsorbate associated with the current spikes at approximately $1.06 \mathrm{~V}$ remains ambiguous. Consequently, it is one of the open problems in electrochemistry and surface science with several unsolved issues: (1) Are water or hydronium molecules coadsorbed with each sulfate or bisulfate? And if so, how many? (2) What is the detailed hydrogen-bonding network that comprises the two-dimensional crystalline adstructure? Importantly, such observations and open questions also exist for other $\mathrm{M}(111) / \mathrm{H}_{2} \mathrm{SO}_{4}$ solution interfaces $(\mathrm{M}=\mathrm{Pt}, \mathrm{Rh}, \mathrm{Cu}$, $\mathrm{Ir}$, and $\mathrm{Pd}){ }^{18-22}$ where the $(\sqrt{3} \times \sqrt{7})$ adstructures prevail as revealed by EC-STM, but the atomistic structures of these interfaces are also ambiguous. ${ }^{13,23-25}$

The difficulties in unambiguously determining the adstructure of the $\mathrm{Au}(111)(\sqrt{3} \times \sqrt{7})$-adsorbate in previous studies are threefold: (1) The spatial resolution of the EC-STM twenty years ago is not sufficiently high to resolve the atomistic details of adsorbates as sulfate or bisulfate anions, water molecule or hydronium cation; (2) The vibrational frequencies of the EC-IR spectra reported in the literature are higher than $900 \mathrm{~cm}^{-1}$ and feature only one or two vibrational modes associated with the sulfate or bisulfate species, while vibrational modes with frequencies below $500 \mathrm{~cm}^{-1}$, associated with the adsorbate-surface interactions, are missing; (3) Quantitative theoretical methods is lacking to calculate the EC-IR and EC-Raman spectra from single crystal electrode/electrolyte interfaces, which plays essential roles in unambiguously interpreting the measured spectra. Therefore, we herein combine the latest experimental and corresponding computational methods to revisit this classic system by unambiguously revealing the atomistic arrangements of adsorbed anions in association with co-adsorbed species. The revisit study could also deepen our understanding of the interactions in the inner Helmholtz plane, which is the heart of the electric double layer at the interface..$^{1,26-29}$

In this study, we employed high-resolution EC-STM combined with DFT calculation to quantitatively assign the atomistic arrangement of the adstructure. Our in-situ electrochemical shell-isolated nanoparticle-enhanced Raman spectroscopy (EC-SHINERS) accompanied with EC-IR spectral data in the literature were employed to unveil the chemical bonding of both sulfate anions and water molecules in the $(\sqrt{3} \times \sqrt{7})$ adstructure. SHINERS has been proven to provide 4-6 orders of magnitude enhancement in Raman signals of adsorbates on metallic (e.g., $\mathrm{Au}, \mathrm{Cu}, \mathrm{Pt}, \mathrm{Rh}$ ) singlecrystal electrodes ${ }^{30-33}$ (see the working principles of SHINERS on transition-metal surfaces in Figure S1). To accurately interpret the features of the experimental spectra, we employed our newly developed computational method to calculate the EC-IR and EC-Raman spectra of nine possible configurations of $\operatorname{Au}(111)(\sqrt{3} \times \sqrt{7})-X \quad(X$ denotes the speculated adsorbates). ${ }^{34}$ This computational method can quantitatively calculate the electrochemical Stark tuning slope (the slope of the vibrational frequency as a function of the applied potential) and, importantly, the spectral intensities of adstructures at the single-crystal electrodes/liquid interfaces by simultaneously considering the surface charge, solvation effect, and high precision requirement for calculating the spectral intensities. ${ }^{34} \mathrm{We}$ found that the calculated EC-STM image, EC-IR and EC-Raman spectra of the $\mathrm{Au}(111)(\sqrt{3} \times \sqrt{7})$ $\left(\mathrm{SO}_{4} \cdots \mathrm{w}_{2}\right)$ configuration perfectly match the respective experimental observations. Finally, we sketched a reaction free energy $\left(\Delta G_{\mathrm{re}}\right)$ diagram ${ }^{25}$ by calculating the potentialdependent Gibbs free energies $G_{\text {ads }}(V)$ of all configurations to further confirm the energetic preference for the adstructure, $\mathrm{Au}(111)(\sqrt{3} \times \sqrt{7})-\left(\mathrm{SO}_{4} \cdots \mathrm{W}_{2}\right)$. The diagram also reveals that the potential-dependent interplay between the proton affinity of sulfate anions and the electrostatic potential energy determines the structural transformation at the EC interfaces. Our work not only elucidates the detailed adsorption configuration at the $\mathrm{Au}(111) / \mathrm{H}_{2} \mathrm{SO}_{4}$ solution interface, but also provides a paradigm for the combined theory/experimental tool kit to unveil the atomistic structures at electrodes/electrolyte interfaces.

\section{EXPERIMENTAL SECTION}

Chemicals. Sulfuric acid (96\%) was purchased from Merck. Deionized Milli-Q water (resistivity of $18.2 \mathrm{M} \Omega \mathrm{cm}$ ) was used for all aqueous solutions.

Preparation of the $\mathrm{Au}(111)$ single crystal electrodes. The $\mathrm{Au}(111)$ half-bead single crystal electrodes were prepared following Clavilier's method ${ }^{35}$ and used as the working electrodes. The surface area of the $\mathrm{Au}(111)$ electrode is $3.733 \mathrm{~mm}^{2}$.

Electrochemical measurements. Cyclic voltammetry (CV) experiments were performed on a $\mathrm{CHI}$ electrochemical workstation (CHI 660D, CH Instrument). A Au wire was used as the counter electrode and a reversible hydrogen electrode (RHE) connected to the cell via a Luggin capillary was used as the reference electrode.

STM measurements. In-situ STM measurements were performed on a Nanoscope V STM instrument (Veeco, Santa Barbara, CA). Mechanically cut Pt/Ir tips were used, which were insulated by apiezon wax or thermosetting glue to reduce the electrochemical current. The STM works in the constant current mode, and the scanning range is $4 \mathrm{~nm} \times 4 \mathrm{~nm}$.

Raman spectroscopic measurements. Pinhole-free $\mathrm{Au} @ \mathrm{SiO}_{2}$ nanoparticles with a $\mathrm{Au}$ core diameter of $\sim 55 \mathrm{~nm}$ and $\mathrm{a} \mathrm{SiO}_{2}$ shell thickness of $\sim 3 \mathrm{~nm}$ were synthesized according to Li's methods. ${ }^{30} \mathrm{Au} @ \mathrm{SiO}_{2} \mathrm{NPs}$ were introduced onto the $\mathrm{Au}(111)$ single crystal electrodes by dropping a dilute $\mathrm{Au} @ \mathrm{SiO}_{2}$ sol solution, followed by the evaporation of the solvent water in the sol. Raman spectra were acquired with a Renishaw InVia Qontor confocal Raman instrument. The 
(B)

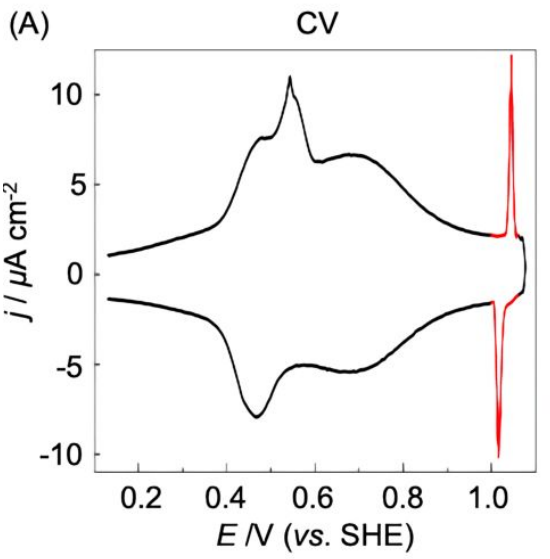

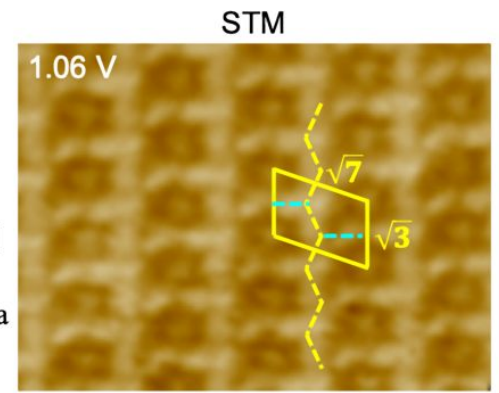

(D)

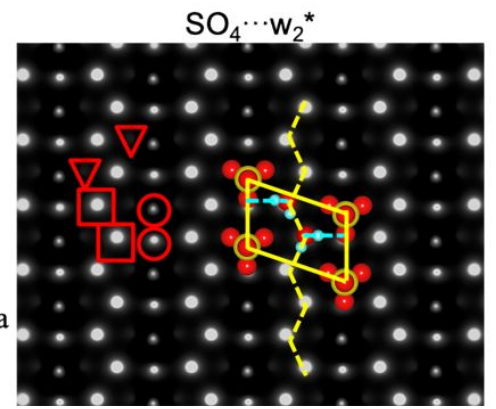

(C)

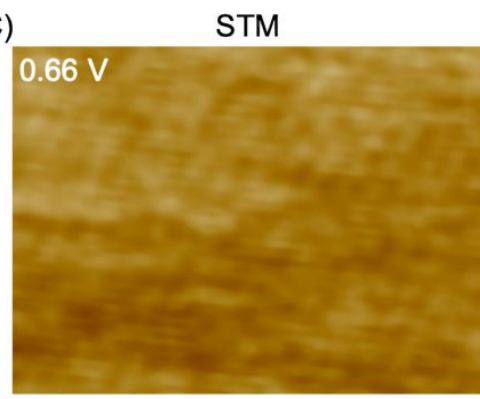

(E)

Charge density

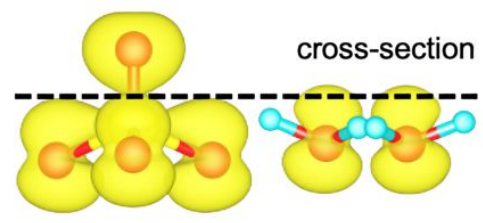

Figure 1. Probing atomistic structures in the $\mathrm{Au}(111) / \mathrm{H}_{2} \mathrm{SO}_{4}$ solution interface. (A) Cyclic voltammetry curve of $\mathrm{Au}(111)$ in $0.1 \mathrm{M} \mathrm{H}_{2} \mathrm{SO}_{4}$ aqueous solution, scan rate: $20 \mathrm{mV} / \mathrm{s}$. (B) and (C) High resolution STM image at $1.06 \mathrm{~V}$ and $0.66 \mathrm{~V} v s$. SHE, respectively. (D) Calculated STM image of the $\mathrm{Au}(111)(\sqrt{3} \times \sqrt{7})-\left(\mathrm{SO}_{4} \cdots \mathrm{w}_{2}\right)$ configuration. (E) Distribution of charge density of the $\mathrm{SO}_{4} \cdots \mathrm{w}_{2} *$ configuration near the Fermi level $E_{\mathrm{F}}$. The unit vectors $\boldsymbol{a}, \boldsymbol{b}$ are the basic vectors of the $\mathrm{Au}(111)(1 \times 1)$ along with the $\left[\begin{array}{ll}\mathbf{1} & \mathbf{\mathbf { 1 }}\end{array}\right]$ and $\left[\begin{array}{l}\mathbf{0} \\ \mathbf{1}\end{array}\right]$ directions, respectively. The basic vectors of $\mathrm{Au}(111)(\sqrt{ } 3 \times \sqrt{7})$ are defined as $2 \boldsymbol{b}-\boldsymbol{a}(\sqrt{3}$ direction) and $2 \boldsymbol{a}+\boldsymbol{b}(\sqrt{7}$ direction), respectively. The main maxima, secondary maxima and minima spots correspond to red panes, circle and triangle frames, respectively.

excitation line was $632.8 \mathrm{~nm}$ from $\mathrm{He}-\mathrm{Ne}$ laser. Electrochemical control was maintained using the $\mathrm{CHI}$ electrochemical workstation. A homemade spectroelectrochemical cell with a Pt wire counter electrode and RHE reference electrode was used for the EC-SHINERS experiments.

DFT calculations. The metal surfaces were modeled as a symmetric $\mathrm{Au}(111)(\sqrt{ } 3 \times \sqrt{ } 7)$ slab with a lattice constant of 4.21 $\AA$ and a thickness of 7 layers in a periodic box of $78.03 \AA$ (the middle three layers were frozen in the bulk position). The first-principles computations were performed using the Vienna ab initio simulation package (VASP) with projector augmented wave (PAW) pseudopotentials. ${ }^{36-37}$ The alternative revision of the Perdew-Burke-Ernzerhof functional, RPBE, was employed to calculate the chemisorption energies of the adsorbates on the $\mathrm{Au}(111)$ surface. ${ }^{38} \mathrm{We}$ considered a $550 \mathrm{eV}$ plane-wave energy cut-off and integrated the Brillouin zone with a $5 \times 5 \times 1 \Gamma$-centered K-point mesh for a $(\sqrt{ } 3 \times \sqrt{ } 7)$ unit cell. The self-consistent field procedure was repeated until reaching a precision of $1 \times 10^{-9} \mathrm{eV}$ in the total energy. All geometries were optimized to reach residual forces on all atoms lower than $0.01 \mathrm{eV} / \AA$. The simulated STM images are constructed on the basis of Tersoff-Hamann theory with a bias voltage of + $0.85 \mathrm{~V}$ and were visualized using the p4vasp program. ${ }^{39}$ To calculate the EC-IR and -Raman spectra, VASPsol implementation was employed to mimic surface solvation effect. ${ }^{40}$ The relative permittivity $\mathcal{E}_{\mathrm{r}}$ and ionic strength $I$ were set to 78 and $0.3 \mathrm{M}$ (corresponding to Debye screening length $\lambda, 5.5 \AA$ ), respectively. The surface tension was set to zero (no cavitation energy). Finite difference method was employed to calculate the IR and Raman spectra. The differential step size of Cartesian coordinates $\Delta x$ and electrostatic field strengths along the $z$ axis $\Delta G_{z}$ were set to $0.01 \AA$ and $0.1 \mathrm{~V} / \AA$, respectively. The detailed computational methods of EC-IR and -Raman spectra were listed in ref. 34. Other computational details are provided in the SI.

\section{RESULTS AND DISCUSSION}

A typical $\mathrm{CV}$ of the $\mathrm{Au}(111)$ electrode in $0.1 \mathrm{M} \mathrm{H}_{2} \mathrm{SO}_{4}$ was recorded from 0.05 to $1.2 \mathrm{~V}$ vs. SHE away from the characteristic voltages regarding hydrogen or oxygen evolution processes (Figure 1A). The CV shows a pair of sharp spikes at approximately $1.06 \mathrm{~V}$ (red lines), which is consistent with the results from the literature, ${ }^{15,41-42}$ and indicates the high quality of the $\mathrm{Au}(111)$ single-crystal electrode in this work.

Determining the adstructure from nine possible configurations at high potentials. In Figure $1 \mathrm{~B}$, the measured EC-STM image at potentials of $1.06 \mathrm{~V}$ and above (1.06-1.20 V, high potentials) exhibits the well-known $(\sqrt{3} \times \sqrt{7})$ adstructure rotated by $19.1^{\circ}$ from the $[1 \overline{1} 0]$ direction of the $\mathrm{Au}(111)$ surface, with the bright spots at the corners of the yellow $(\sqrt{3} \times \sqrt{7})$ frame. The STM image shows many detailed features that were not resolved before. ${ }^{10-11,15,42}$ In particular, we observed zig-zag chains (dashed yellow line segments along the $\sqrt{3}$ direction) and two lobes (dashed cyan lines along the direction of $\boldsymbol{a}$ ) going through and inside the yellow frame, respectively. Once the potential is moved to below $1.06 \mathrm{~V}$, ordered structures disappear and surface become blurry with scratching (Figure 1C), which indicates that the adlayer becomes disordered.

To assign the observed ultrafine features in the measured STM image (Figure 1B), we compared it with the DFT simulated EC-STM images of nine possible configurations (Figure 2) which were extracted from the literature. ${ }^{10-}$ $13,15,17,23,43-44$ See detailed atomistic labels such as O1, O2, O3 and $\mathrm{O} 4$ from the $\mathrm{SO}_{4} *$ or $\mathrm{HSO}_{4} *$ in Figure $2 \mathrm{~A}$ and the caption of Figure 2. 
(A) O1-Au1 O3-Au3(B)
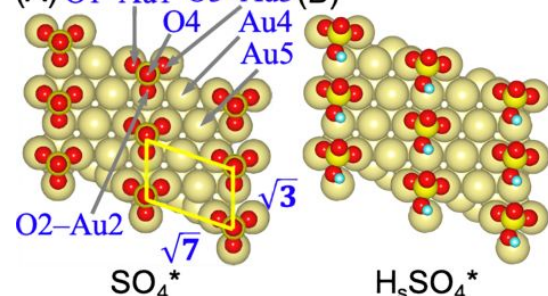

$\mathrm{H}_{\mathrm{S}} \mathrm{SO}_{4}{ }^{*}$

(C)
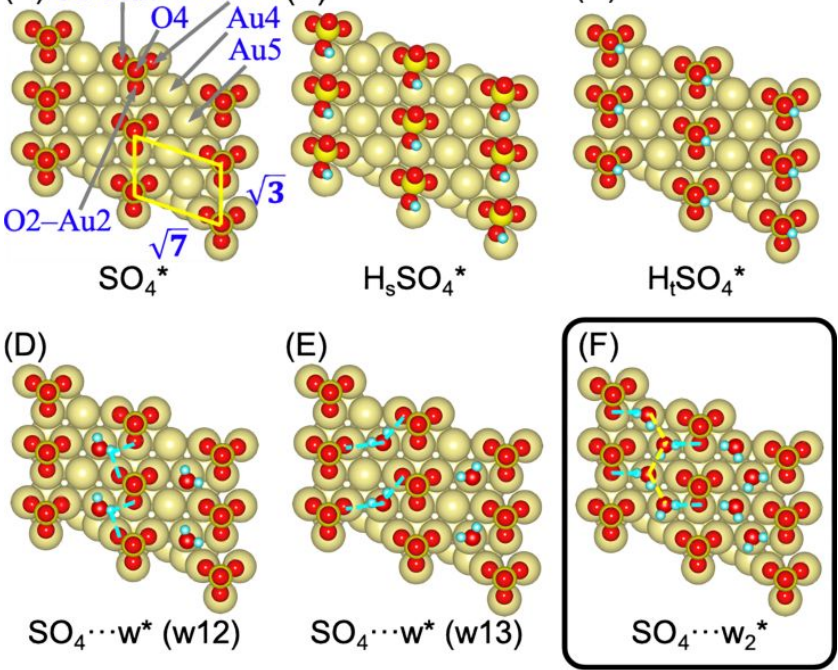

(G)

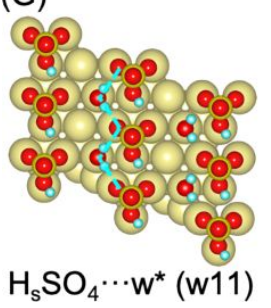

(H)

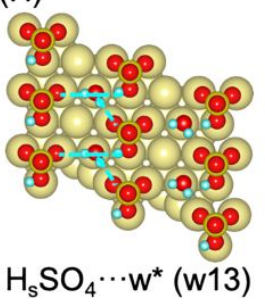

(I)

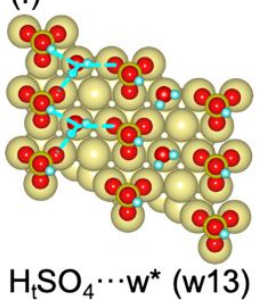

Figure 2. Nine proposed $\mathrm{Au}(111)(\sqrt{ } 3 \times \sqrt{7})-\mathrm{X}$ configurations with different adsorbates X. (A) $\mathrm{SO}_{4}{ }^{*}$; (B) and (C) $\mathrm{H}_{\mathrm{s}} \mathrm{SO}_{4}{ }^{*}$ and $\mathrm{H}_{\mathrm{t}} \mathrm{SO}_{4}$ * with $\mathrm{H}$ bonding with $\mathrm{O} 2$ and $\mathrm{O} 4$, respectively; (D) and (E) $\mathrm{SO}_{4} \cdots \mathrm{w}^{*}(\mathrm{w} 12)$ and $\mathrm{SO}_{4} \cdots \mathrm{w}^{*}(\mathrm{w} 13)$ consist of a sulfate anion and a co-adsorbed water molecule with $\mathrm{SO}_{4} \cdots \mathrm{w}^{*}$ hydrogen-bonds through $\mathrm{O} 1$ and $\mathrm{O} 2$ or $\mathrm{O} 1$ and $\mathrm{O} 3$, respectively; (F) $\mathrm{SO}_{4} \cdots \mathrm{w}_{2} *$ consists of a sulfate anion and a co-adsorbed dual-water $\left(\mathrm{w}_{2}\right)$ molecules; (G) and (H) $\mathrm{H}_{\mathrm{s}} \mathrm{SO}_{4} \cdots \mathrm{w}^{*}$ (w11) and $\mathrm{H}_{\mathrm{s}} \mathrm{SO}_{4} \cdots \mathrm{w}^{*}$ (w13) consist of a bisulfate anion with $\mathrm{H}$ bonding with $\mathrm{O} 2$ and a coadsorbed water molecule with $\mathrm{H}_{\mathrm{s}} \mathrm{SO}_{4} \cdots \mathrm{w}^{*}$ hydrogen-bonds through $\mathrm{O} 1$ and $\mathrm{O} 1$ or $\mathrm{O} 1$ and $\mathrm{O} 3$ from different $\mathrm{H}_{5} \mathrm{SO}_{4} *$ molecules; (I) $\mathrm{H}_{\mathrm{t}} \mathrm{SO}_{4} \cdots \mathrm{W}^{*}(\mathrm{w} 13)$ consists of a bisulfate anion with $\mathrm{H}$ bonding with $\mathrm{O} 4$ and a co-adsorbed water molecule with $\mathrm{H}_{\mathrm{t}} \mathrm{SO}_{4} \cdots \mathrm{w}^{*}$ hydrogen-bonds through $\mathrm{O} 1$ and $\mathrm{O} 3$ from different $\mathrm{H}_{\mathrm{t}} \mathrm{SO} 4 *$ molecules. The golden, yellow, red, and cyan balls denote $\mathrm{Au}, \mathrm{S}, \mathrm{O}$, and $\mathrm{H}$ atoms, respectively. The dashed cyan and yellow lines denote (bi)sulfate-water hydrogen bonds and waterwater hydrogen bonds, respectively.

Neither the zig-zag feature nor the two-lope feature in the measured STM image can be reproduced from any other configurations except for the $\mathrm{Au}(111)(\sqrt{3} \times \sqrt{7})-\left(\mathrm{SO}_{4} \cdots \mathrm{w}_{2}\right)$ (Figure S2). The calculated STM pattern (Figure 1D) of $\mathrm{Au}(111)(\sqrt{3} \times \sqrt{7})-\left(\mathrm{SO}_{4} \cdots \mathrm{w}_{2}\right)$ perfectly matches the measured one at high potentials (Figure 1B). The zig-zag chains are assigned to hydrogen-bonded dual-water molecules (Figure $1 \mathrm{~B}$ and $1 \mathrm{D})$. The two lobes are assigned to the side oxygen atoms $\mathrm{O} 2$ of two adjacent $\mathrm{SO}_{4}{ }^{*}$ molecules (along the $\sqrt{7}$ direction) which are hydrogen-bonded with the two water molecules. As we know, the spot brightness in the STM image depends on the cross-section of the oxygen charge density near the Fermi level $E_{\mathrm{F}}$ in $\mathrm{Au}(111)(\sqrt{3} \times \sqrt{7})$-X. Thus, the main maxima spots (marked with two red open squares, aligned along the zig-zag chains in Figure 1D), secondary maxima spots (marked with two red open circles, aligned along the $\sqrt{3}$ direction), and minima spots (marked with two red open triangles, intertwined with the main maxima spots) in the

$(\sqrt{3} \times \sqrt{7})$ unit cell are, respectively, associated with the charge densities of $\mathrm{O}$ atoms from the dual-water molecules hydrogenbonded with each other, $\mathrm{O} 2$ and $\mathrm{O} 4$ atoms of the $\mathrm{SO}_{4}{ }^{*}$, and $\mathrm{O} 1$ and $\mathrm{O} 3$ atoms of the $\mathrm{SO}_{4}{ }^{*}$, since their cross-sections decrease in turn (Figure 1E). In short, the measured and calculated ECSTM images reveal that the adstructure is $\mathrm{Au}(111)(\sqrt{ } 3 \times \sqrt{7})$ $\left(\mathrm{SO}_{4} \cdots \mathrm{W}_{2}\right)$ with a sulfate anion $\left(\mathrm{SO}_{4}{ }^{*}\right)$ and two structuredwater molecules $\left(\mathrm{w}_{2}{ }^{*}\right)$ in a unit cell, and the crisscrossed $\left[\mathrm{w} \cdots \mathrm{SO}_{4} \cdots \mathrm{w}\right]_{\mathrm{n}}$ and $[\mathrm{w} \cdots \mathrm{w} \cdots]_{\mathrm{n}}$ hydrogen-bonding network comprises the symmetric adstructure.

EC-IR spectroscopy can provide chemical-bonding information on the sulfate anions and the co-adsorbed water molecules or hydronium cations in the adstructure of $\mathrm{Au}(111)(\sqrt{3} \times \sqrt{7})-\mathrm{X}$ at the high potentials. The EC-IR spectrum (the dark red curve in Figure 3A) at $1.06 \mathrm{~V}$ measured by Ataka et al., ${ }^{12}$ features three main bands centered at 955, 1183, and $1650 \mathrm{~cm}^{-1}$, which have been assigned to the symmetric stretching mode in $\mathrm{SO}_{4} v_{\mathrm{s}}\left(\mathrm{SO}_{4}\right), \mathrm{S}-\mathrm{O}$ (of uncoordinated oxygen atom, $\mathrm{O} 4$ in Figure $2 \mathrm{~A})$ bond stretching mode $v\left(\mathrm{SO}_{\mathrm{uc}}\right)$ of $\mathrm{SO}_{4}{ }^{*}$, and bending mode of $\mathrm{w}^{*}, \delta\left(\mathrm{H}_{2} \mathrm{O}\right)$ by the authors. The experimental assignment alone cannot provide a conclusive determination of adstructures. However, the simulated EC-IR spectra of all possible configurations, accompanied with the measured EC-IR spectra can evidentially help us to exclude most of the candidate configurations and identify the most possible one. Figures $3 \mathrm{~A}$ and $3 \mathrm{~B}$ show that the possible configurations with $\mathrm{H}_{\mathrm{t}} \mathrm{SO}_{4} \cdots \mathrm{w}^{*}$ (w13), $\mathrm{H}_{\mathrm{s}} \mathrm{SO}_{4} \cdots \mathrm{w}^{*}$ (w13), or $\mathrm{H}_{\mathrm{S}} \mathrm{SO}_{4} \cdots \mathrm{w}^{*}$ (w11) can be excluded since the calculated bands at 1226 or $1243 \mathrm{~cm}^{-1}$ assigned to the $v\left(\mathrm{SO}_{\mathrm{uc}}\right)$ mode of $\mathrm{HSO}_{4}{ }^{*}$, cannot be observed in the measured EC-IR spectrum (see the modes in Figure S11-S13). The possible configurations with $\mathrm{SO}_{4} \cdots \mathrm{w}^{*}$ (w12), $\mathrm{SO}_{4}{ }^{*}$, or $\mathrm{H}_{\mathrm{s}} \mathrm{SO}_{4}{ }^{*}, \mathrm{H}_{\mathrm{t}} \mathrm{SO}_{4}{ }^{*}$ can also be excluded due to the absence of the $\delta\left(\mathrm{H}_{2} \mathrm{O}\right)$ bands at around $1650 \mathrm{~cm}^{-1}$. Additionally, the $\mathrm{SO}_{4} \cdots \mathrm{w}^{*}$ (w13) configuration can be excluded because a pair of splitting bands at 944 and $974 \mathrm{~cm}^{-1}$ due to the decrease of the sulfate anion symmetry, poorly match the single band at $956 \mathrm{~cm}^{-1}$ in the measured ECIR spectrum. The previously suggested well-known $\mathrm{Au}(111)(\sqrt{3} \times \sqrt{7})-\left(\mathrm{SO}_{4} \cdots \mathrm{H}_{3} \mathrm{O}\right)$ configuration ${ }^{17,44}$ can be excluded for two reasons: (i) The characteristic hydronium band at around $1700 \mathrm{~cm}^{-1}$ cannot be observed in the EC-IR spectra at high potentials; 45 (ii) Computationally, configurations with a co-adsorbed hydronium cannot be optimized at high potentials, but converge to $\mathrm{HSO}_{4} \cdots \mathrm{w}$ * configurations. In short, only the calculated EC-IR spectrum of $\mathrm{Au}(111)(\sqrt{ } 3 \times \sqrt{7})-\left(\mathrm{SO}_{4} \cdots \mathrm{w}_{2}\right)$ matches well the measured one.

To understand the IR activity of the $\delta\left(\mathrm{H}_{2} \mathrm{O}\right)$ bands of the possible configurations, we analyzed the orientation of the dipole of $\mathrm{w}^{*}, \theta_{\mathrm{w}}$, defined as the included angle between the dipole moment of $\mathrm{w}^{*}$ and the surface normal of the $\mathrm{Au}(111)$ electrode. The $\theta_{\mathrm{w}}$ angels in $\mathrm{SO}_{4} \cdots \mathrm{w}^{*}(\mathrm{w} 12)$ and $\mathrm{H}_{\mathrm{s}} \mathrm{SO}_{4} \cdots \mathrm{w}^{*}$ (w13) are $79^{\circ}$ and $98^{\circ}$, respectively. As a result, the $\delta\left(\mathrm{H}_{2} \mathrm{O}\right)$ bands of the two possible configurations are almost IRinactive according to the surface selection rule of surface IR spectroscopy on metal surfaces. ${ }^{26}$ In $\mathrm{SO}_{4} \cdots \mathrm{w}_{2}{ }^{*}$, the $\theta_{\mathrm{w}}$ angles of both water molecules are almost identical $\left(67^{\circ}\right)$. The band centered at $1669 \mathrm{~cm}^{-1}$ of $\mathrm{SO}_{4} \cdots \mathrm{w}_{2}{ }^{*}$ is assigned to the symmetric bending mode $\delta_{\mathrm{s}}\left(\mathrm{H}_{2} \mathrm{O}\right)$ of dual hydrogen-bonded water molecules, and is IR-active; the anti-symmetric bending mode $\delta_{\text {anti }}\left(\mathrm{H}_{2} \mathrm{O}\right)$ centered at $1685 \mathrm{~cm}^{-1}$ is, however, IRinactive. 
(A)

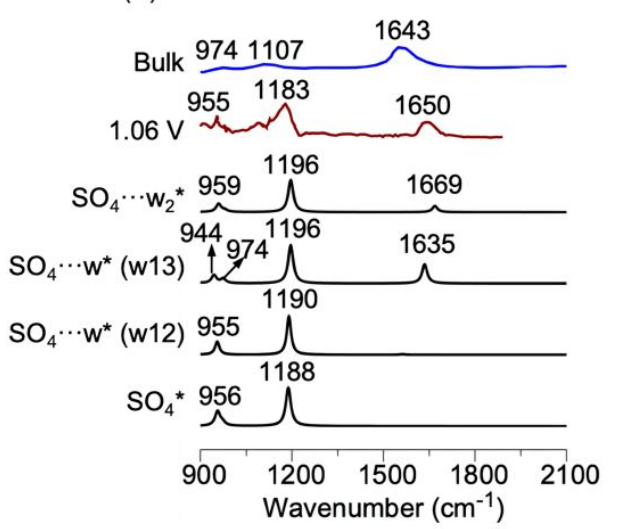

IR

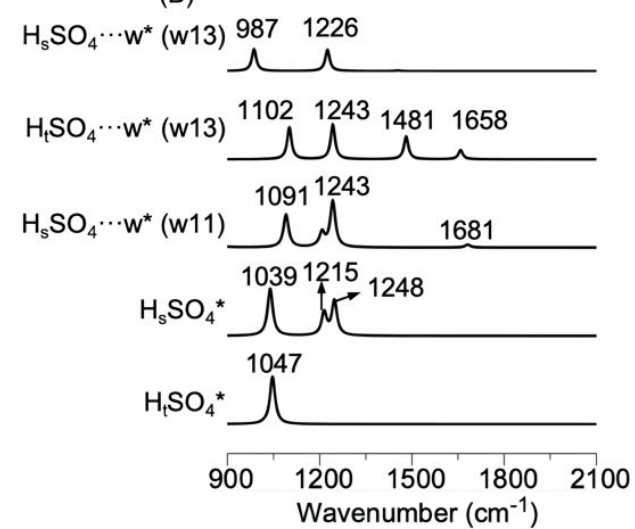

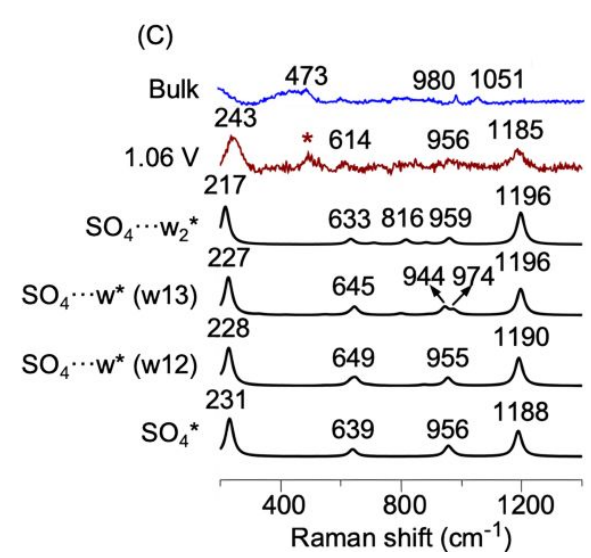

Raman

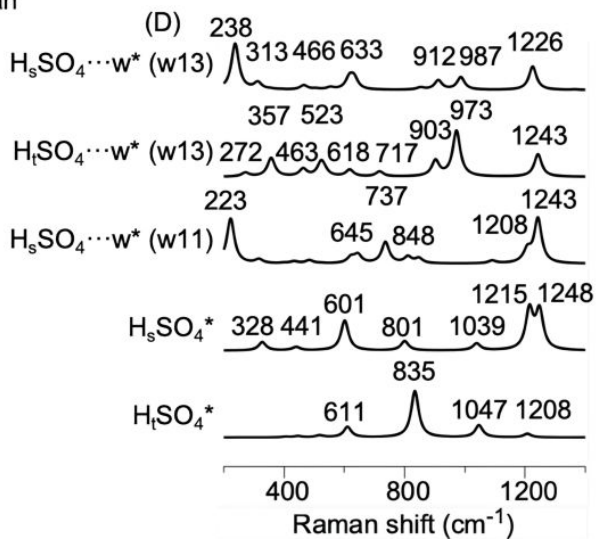

Figure 3. Calculated EC-IR and -Raman spectra of the $\mathrm{Au}(111)(\sqrt{3} \times \sqrt{7})-\mathrm{X}$ configurations at $1.06 \mathrm{~V} v$ s. SHE. EC-IR spectra of the configurations containing sulfate anions in (A) or bisulfate anions in (B). EC-Raman spectra of the configurations containing sulfate anions in (C) or bisulfate anions in (D). The blue curves in panel A and C, respectively, denote the measured IR and Raman spectrum of bulk solution. The dark red curves in panel A and C, respectively, denote the measured EC-IR and -Raman spectrum at 1.06 V. The measured IR spectra were adapted from ref. 12 with permission, copyright (1998) American Chemical Society.

The EC-Raman spectroscopy has the advantage over the EC-IR counterpart to provide much richer vibrational fingerprint information on the sulfate or bisulfate anions with vibrational frequencies of $100-1300 \mathrm{~cm}^{-1}$. However, it is difficult to obtain high signal-to-noise EC-SHINERS spectra in this study due to the weak Raman activity of the interfacial species in this system. The primarily measured potentialdependent Raman spectra are shown in Figure S3. For comparison with the measured EC-Raman spectra, the Raman spectrum from the bulk solution was taken first (the blue curve in Figure 3C). Three main bands centered at 473, 980, and $1051 \mathrm{~cm}^{-1}$ are shown and assigned to the combinational $\mathrm{SO}_{2}$ wagging and rocking modes $\rho_{\mathrm{w}+\mathrm{r}}\left(\mathrm{SO}_{2}\right)$, symmetric $\mathrm{SO}_{4}$ stretching mode $v_{\mathrm{s}}\left(\mathrm{SO}_{4}\right)$, and symmetric $\mathrm{SO}_{3}$ stretching mode $v_{\mathrm{s}}\left(\mathrm{SO}_{3}\right)$, respectively (see the detailed analyses in SI 6 and modes in Figures S4-S6). The EC-SHINER spectrum at 1.06 $\mathrm{V}$ (dark red curve in Figure 3C) and above shows four bands at $243,614,956$, and $1185 \mathrm{~cm}^{-1}$. The considerable difference between the EC-SHINER spectrum and the bulk Raman spectrum indicates that the four bands arise from vibrational modes of the interfacial species instead of bulk species.

The calculated EC-Raman spectra for the configurations that containing adsorbed sulfate anions $\left(\mathrm{SO}_{4} \cdots \mathrm{w}_{2}{ }^{*}, \mathrm{SO}_{4} \cdots \mathrm{w}^{*}\right.$ (w12), and $\mathrm{SO}_{4}{ }^{*}$ (Figure 3C)) show four bands at 217-231, 633-649, 944-959 and 1188-1196 cm $\mathrm{cm}^{-1}$, which in some extent agree with the measured spectrum counterparts at $1.06 \mathrm{~V}$. The $\mathrm{SO}_{4} \cdots \mathrm{w}^{*}$ (w13) configuration can, however, be excluded, as the pair of splitting bands at $955 \mathrm{~cm}^{-1}$ cannot be observed in the measured one. Moreover, the Stark tuning slopes (STS) of the four bands in the measured Raman spectra also in some extent agree with the calculated Raman spectra of the three configurations counterparts, as shown in Table 1. Particularly, the 956 and $1185 \mathrm{~cm}^{-1}$ frequencies of the measured ECRaman bands at $1.06 \mathrm{~V}$ perfectly match the frequencies 955 and $1183 \mathrm{~cm}^{-1}$ of the measured EC-IR spectrum at $1.06 \mathrm{~V}$ (Figure 3A and 3C, dark red curves). Furthermore, the STS of the $1185 \mathrm{~cm}^{-1}$ band $\left(59 \mathrm{~cm}^{-1} \mathrm{~V}^{-1}\right)$ in the measured EC-Raman spectra perfectly matches those of the measured EC-IR band at $1189 \mathrm{~cm}^{-1}\left(45 \mathrm{~cm}^{-1} \mathrm{~V}^{-1}\right)$ by Edens et al. ${ }^{11}$ and the IR band at $1183 \mathrm{~cm}^{-1}\left(60 \mathrm{~cm}^{-1} \mathrm{~V}^{-1}\right)$ by Ataka et al. ${ }^{12}$ Therefore, the observed bands at $243,614,956$, and $1185 \mathrm{~cm}^{-1}$ of the Raman spectrum at $1.06 \mathrm{~V}$, are assigned to the out-of-surface translational-like mode of $\mathrm{SO}_{4} * T\left(\mathrm{Au}-\mathrm{SO}_{4}\right)$, symmetric $\mathrm{SO}_{3}$ bending mode

Table 1. STSs $\left(\mathrm{cm}^{-1} \mathrm{~V}^{-1}\right)$ of the vibrational frequencies for the adsorbed sulfate configurations at the high potentials.

\begin{tabular}{lcccc}
\hline Modes & $T\left(\mathrm{Au}-\mathrm{SO}_{4}\right)$ & $\delta_{\mathrm{s}}\left(\mathrm{SO}_{3}\right)$ & $v_{\mathrm{s}}\left(\mathrm{SO}_{4}\right)$ & $\begin{array}{c}v(\mathrm{SO} \\
\text { uc }\end{array}$ \\
\hline Expt. & 34 & 0 & -33 & 59 \\
$\mathrm{SO}_{4} \cdots \mathrm{w}_{2}{ }^{*}$ & 27 & 0 & -10 & 34 \\
$\mathrm{SO}_{4} \cdots \mathrm{w}^{*}(\mathrm{w} 13)$ & 35 & 20 & -17 & 36 \\
$\mathrm{SO}_{4} \cdots \mathrm{w}^{*}(\mathrm{w} 12)$ & 34 & -5 & -13 & 28 \\
$\mathrm{SO}_{4}{ }^{*}$ & 25 & -3 & -15 & 30 \\
\hline
\end{tabular}


$\delta_{\mathrm{s}}\left(\mathrm{SO}_{3}\right), v_{\mathrm{s}}\left(\mathrm{SO}_{4}\right)$ mode, and $v\left(\mathrm{SO}_{\mathrm{uc}}\right)$ mode (Figure $\left.\mathrm{S} 7-\mathrm{S} 10\right)$, respectively.

The configurations containing $\mathrm{HSO}_{4}{ }^{*}$ at the high potentials can be excluded, since their bands at 300-400 and 800-900 $\mathrm{cm}^{-1}$ (Figure 3D) cannot match any of those in the measured EC-Raman spectrum. The vibrational modes of the configurations containing $\mathrm{HSO}_{4}{ }^{*}$ have been visualized and listed in Figures S11-S15. Briefly, the EC-Raman spectra reveal that the adstructure must contain sulfate anions instead of bisulfate anions, which supports the main conclusion drawn by chronocoulometry and radiochemistry studies. ${ }^{16}$ However, the EC-Raman spectra cannot provide strong evidence to determine the number and atomistic arrangements of coadsorbed water molecules, which might due to the ultraweak cross section of water molecules. Nevertheless, according to joint evidence from the calculated and measured EC-Raman and EC-IR spectra, the $\mathrm{Au}(111)(\sqrt{3} \times \sqrt{7})-\left(\mathrm{SO}_{4} \cdots \mathrm{w}_{2}\right)$ configuration is the most plausible adstructure at high potentials.

Adstructure of the $\mathrm{Au}(111) / \mathrm{H}_{2} \mathrm{SO}_{4}$ solution interface at the low potentials. The EC-Raman spectra also show that the band at approximately $300 \mathrm{~cm}^{-1}$ gradually appears, and the 614 and $1185 \mathrm{~cm}^{-1}$ bands diminish when the potential is negatively shifted to the range of $0.66-0.86 \mathrm{~V}$ (low potentials). In addition, the STSs at 243,956 , and $1185 \mathrm{~cm}^{-1}$ at high potentials $\left(34,-33\right.$, and $59 \mathrm{~cm}^{-1} \mathrm{~V}^{-1}$, respectively) are apparently different from the respective STSs of $24,-25$, and $90 \mathrm{~cm}^{-1} \mathrm{~V}^{-1}$ below $0.86 \mathrm{~V}$. The discrepancies of the spectral features at high and low potentials indicate that the interface undergoes a potential-determined structural transformation in the potential range of $0.86-1.06 \mathrm{~V}$.

Although the measured STM image in Figure 1C shows that the interfacial structures at the low potentials may be disordered in the acquisition time domain, the theoretical study based on the $\mathrm{Au}(111)(\sqrt{ } 3 \times \sqrt{ } 7)$-X configurations at low potentials is still relevant to determine approximate adstructures containing sulfate or bisulfate by comparing the calculated EC-Raman spectra with the measured one, as shown in Figure S16 and Table S2-S4. The four configurations containing $\mathrm{SO}_{4}{ }^{*}$ can be excluded at the low potentials, because none of their EC-Raman spectra can interpret the appearance of new band at $300 \mathrm{~cm}^{-1}$ and the disappearance of the $1185 \mathrm{~cm}^{-1}$ band of the measured ECRaman spectrum (dark red curves of Figure S16). In contrast, the calculated EC-Raman spectra of $\mathrm{H}_{\mathrm{s}} \mathrm{SO}_{4} \cdots \mathrm{w}^{*}$ (w13) and $\mathrm{H}_{\mathrm{t}} \mathrm{SO}_{4} \cdots \mathrm{W}^{*}(\mathrm{w} 13)$ to some extend match the measured one. The new Raman band at $300 \mathrm{~cm}^{-1}$ is assigned to the $\mathrm{H}_{2} \mathrm{O} \cdots \mathrm{HSO}_{4}$ stretching mode $v(\mathrm{HB})$ (see the modes in Figure $\mathrm{S} 11$ and S12). By further comparing the calculated and measured STSs of the three bands in 231-233, 294-301, 966$988 \mathrm{~cm}^{-1}$, as shown in Table $\mathrm{S} 4$, we deduce that the adstructure is more likely $\mathrm{H}_{\mathrm{s}} \mathrm{SO}_{4} \cdots \mathrm{w}^{*}$ (w13) than $\mathrm{H}_{\mathrm{t}} \mathrm{SO}_{4} \cdots \mathrm{w}^{*}$ (w13) at low potentials.

Reaction free energy diagram and adstructural stability of $\mathbf{A u}(\mathbf{1 1 1})(\sqrt{3} \times \sqrt{7})-X$. The potential-dependent reaction free energies $\Delta G_{\text {re }}$ was calculated to further determine the adstructures at high potentials and the potential-dependent structural transformation. Figure 4 shows that the $\mathrm{Au}(111)(\sqrt{3} \times \sqrt{7})-\left(\mathrm{SO}_{4} \cdots \mathrm{W}_{2}\right)$ (solid red line) is the most stable configuration at high potentials. It also shows that $\mathrm{H}_{\mathrm{t}} \mathrm{SO}_{4} \cdots \mathrm{w}^{*}$ (w13) (solid dark blue line) is the most stable structure at low potentials. However, the $\mathrm{H}_{\mathrm{s}} \mathrm{SO}_{4} \cdots \mathrm{w}^{*}$ (w13) (dashed dark blue

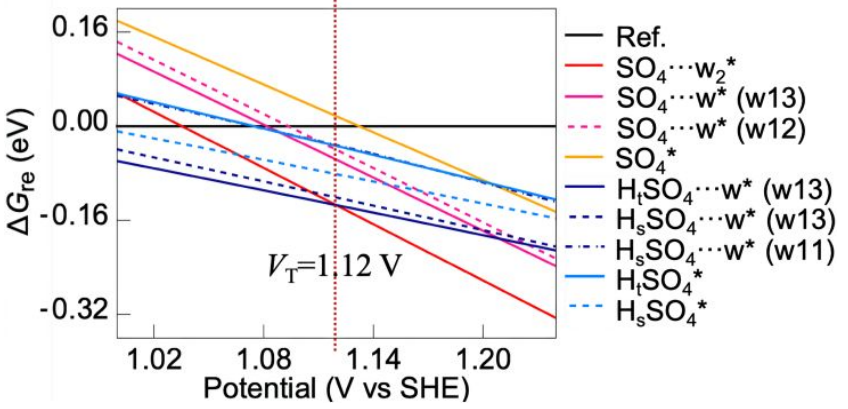

Figure 4. Potential-dependent reaction free energy diagram from $1.00 \mathrm{~V}$ to $1.24 \mathrm{~V} v s$. SHE. The black line denotes the reference state $\left(\mathrm{HSO}_{4}^{-}(\mathrm{aq})+3 \mathrm{H}_{2} \mathrm{O}(\mathrm{aq})+*\right)$. The solid and dashed parabolas denote $\mathrm{X}=\mathrm{H}_{\mathrm{t}} \mathrm{SO}_{4}{ }^{*}$ and $\mathrm{H}_{\mathrm{s}} \mathrm{SO}_{4}{ }^{*}$ in blue, $\mathrm{SO}_{4} \cdots \mathrm{W}$ * (w13) and (w12) in pink, $\mathrm{H}_{t} \mathrm{SO}_{4} \cdots \mathrm{w}^{*}(\mathrm{w} 13)$ and $\mathrm{H}_{\mathrm{s}} \mathrm{SO}_{4} \cdots \mathrm{w}^{*}$ (w13) in dark blue.

line) is only slightly less stable than $\mathrm{H}_{\mathrm{t}} \mathrm{SO}_{4} \cdots \mathrm{w}^{*}$ (w13). The $\Delta G_{\text {re }}$ parabolas of both stable adstructures intersect at $1.12 \mathrm{~V}$ $v s$. SHE, which indicates that a deprotonation reaction (Equation 1) occurs when the potential is positively tuned from low potentials to high potentials. The intersect potential regarding the deprotonation reaction can slightly depend on the ionic strength $I$ (see Figure S17): It shifts negatively by $0.03 \mathrm{~V}$ as the ionic strength decreases from $0.3 \mathrm{M}$ to $0.1 \mathrm{M}$, and it shifts positively by $0.04 \mathrm{~V}$ as the ionic strength increases from $0.3 \mathrm{M}$ to $1.0 \mathrm{M}$.

$$
\mathrm{HSO}_{4} \cdots \mathrm{w}^{*}+\mathrm{H}_{2} \mathrm{O}(\mathrm{aq})-e^{-} \rightarrow \mathrm{SO}_{4} \cdots \mathrm{w}_{2}{ }^{*}+\mathrm{H}^{+}(\mathrm{aq})
$$

To understand the mechanism of the deprotonation reaction, we made a detailed analysis on $\Delta G_{\mathrm{re}}$. Figure S18A shows that the adsorbed bisulfate configurations are more stable than the adsorbed sulfate configurations at low potentials, due to the proton affinity of the adsorbed sulfate anion. When the potential is positively shifted, the electrostatic potential energies of the adsorbed sulfate configurations gradually surpass the sum of the proton affinity and the electrostatic potential energies of the adsorbed bisulfate configurations, which stabilizes the sulfate anion adsorption. Moreover, the co-adsorbed water molecules can hydrogen-bond to the $\mathrm{O}$ atoms from the adjacent water molecule and $\mathrm{O}$ atoms from sulfate anions to effectively stabilize the adstructures, especially at high potentials (Figure S18B).

A limitation of the geometric model for studying the deprotonation mechanism is that the unit cell associated with $\operatorname{Au}(111)(\sqrt{ } 3 \times \sqrt{7})-X$ configurations are too small to describe the disorder adstructure at low potentials (see Figure 1C). Configurations with much larger unit cells such as $\mathrm{Au}(111)(2 \sqrt{3} \times 5)$ or $(2 \sqrt{3} \times 6)$ unit cells would be helpful for studying more configurations with lower coverages at low potentials, and obtaining a more complete deportation mechanism of the $\mathrm{HSO}_{4}{ }^{*}$ species. Moreover, the molecular processes associated with the pair of current spikes are still an open question. At present, we cannot rule out other possible processes such as structural transformation from the disordered $\left(\mathrm{SO}_{4} \cdots \mathrm{w}\right)^{*}$ to ordered $\left(\mathrm{SO}_{4} \cdots \mathrm{w}_{2}\right)^{*}$ due to coadsorption of more water molecules.

\section{CONCLUSION}

By combining experimental and computational EC-STM, EC-IR, and EC-Raman spectroscopy, we conclude that the adstructure is $\mathrm{Au}(111)(\sqrt{3} \times \sqrt{7})-\left(\mathrm{SO}_{4} \cdots \mathrm{w}_{2}\right)$ at high potentials $(>1.06 \mathrm{~V}$ vs SHE); the coadsorbed water molecules play an 
important role in the formation of the ordered $\left(\mathrm{SO}_{4} \cdots \mathrm{W}_{2}\right)^{*}$ adstructure. This discovery deepens our understanding of the interactions in the inner Helmholtz plane. The electroadsorbed species $\mathrm{SO}_{4} \cdots \mathrm{w}_{2}$ * evolves to $\mathrm{H}_{\mathrm{t}} \mathrm{SO}_{4} \cdots \mathrm{W}$ * when the potential is negatively tuned to the low potentials $(<0.86 \mathrm{~V})$. The $\Delta G_{\mathrm{re}}$ diagram reveals that the potential-dependent interplay between the proton affinity of sulfate anions and the electrostatic potential energy determine the potential-tuned structural transformation on the electrode surface.

This work offers a definite answer that clarifies the 40-year ambiguity in the atomistic adstructure at the $\mathrm{Au}(111) / \mathrm{H}_{2} \mathrm{SO}_{4}$ solution interface at high potentials. The determined adstructure $\mathrm{Au}(111)(\sqrt{3} \times \sqrt{7})-\left(\mathrm{SO}_{4} \cdots \mathrm{w}_{2}\right) \quad$ straightforwardly enlightens the studies of similar systems, i.e., other $\mathrm{M}(111) / \mathrm{H}_{2} \mathrm{SO}_{4}$ solution interfaces $(\mathrm{M}=\mathrm{Pt}, \mathrm{Rh}, \mathrm{Cu}$, Ir, and Pd). The experimental and computational EC-STM, EC-IR and EC-Raman spectroscopies, and the computational diagram of the reaction free energy may provide a standard workflow to obtain multi-perspective evidence for atomistic structures of the inner Helmholtz plane. The methods thus pave the way to explore the reaction mechanisms of electrocatalytic or photoelectrocatalytic reactions, electro-corrosion and electrodeposition reactions at atomistic levels.

\section{ASSOCIATED CONTENT}

\section{Supporting Information.}

Computational details, the calculation of reaction free energy, Figure S1-S19, and Table S1-S4

The Supporting Information is available free of charge on the ACS Publications website.

\section{AUTHOR INFORMATION}

\section{Corresponding Author}

syding@xmu.edu.cn

bwmao@xmu.edu.cn

juan.feliu@ua.es

Notes

The authors declare no competing financial interest.

\section{ACKNOWLEDGMENTS}

The authors acknowledge funding supported by the National Natural Science Foundation of China (91950121, 21727807, 21403179, 21872115, and 21533006). The firstprinciples calculations in this work were performed on the supercomputing system in the big data system and computing platform of the State Key Laboratory of Physical Chemistry of Solid Surfaces, Xiamen University. Y.F. and S.Y.D. sincerely thank Dr. Ryosuke Jinnouchi for discussion on the calculation of reaction free energy of $\mathrm{Au}(111)(\sqrt{3} \times \sqrt{ } 7)-\mathrm{X}$ configurations.

\section{REFERENCES}

(1) Zaera, F. Probing liquid/solid interfaces at the molecular level. Chem Rev 2012, 112, 2920-2986.

(2) Schmickler, W.; Santos, E. Interfacial Electrochemistry. Oxford University Press: New York, 1996.

(3) Wieckowski, A. Interfacial Electrochemistry. Theory, Experiment, and Application. Marcel Dekker: New York, 1999.

(4) White, J. H.; Abruna, H. D. Electrosorption of iodide on platinum(111) studied in situ by X-ray absorption spectroscopy. $J$. Phys. Chem. 1988, 92, 7131-7134.
(5) Braunschweig, B.; Mukherjee, P.; Dlott, D. D.; Wieckowski, A. Real-time investigations of $\mathrm{Pt}(111)$ surface transformations in sulfuric acid solutions. J. Am. Chem. Soc. 2010, 132, 14036-14038.

(6) Bodappa, N.; Su, M.; Zhao, Y.; Le, J. B.; Yang, W. M.; Radjenovic, P.; Dong, J. C.; Cheng, J.; Tian, Z. Q.; Li, J. F. Early Stages of Electrochemical Oxidation of $\mathrm{Cu}(111)$ and Polycrystalline $\mathrm{Cu}$ Surfaces Revealed by in Situ Raman Spectroscopy. J. Am. Chem. Soc. 2019, 141, 12192-12196.

(7) Kolb, D. M. Electrochemical surface science. Angew. Chem. Int. Ed. 2001, 40, 1162-1181.

(8) Magnussen, O. M. Ordered Anion Adlayers on Metal Electrode Surfaces. Chem. Rev. 2002, 102, 679-726.

(9) Scherson, D. A.; Kolb, D. M. Voltammetric curves for $\mathrm{Au}(111)$ in acid media: A comparison with $\operatorname{Pt}(111)$ surfaces. $J$. Electroanal. Chem. 1984, 176, 353-357.

(10) Magnussen, O. M.; Hageböck, J.; Hotlos, J.; Behm, R. J. In situ scanning tunnelling microscopy observations of a disorder-order phase transition in hydrogensulfate adlayers on $\mathrm{Au}(111)$. Faraday Discuss. 1992, 94, 329-338.

(11) Edens, G. J.; Gao, X.; Weaver, M. J. The adsorption of sulfate on gold(111) in acidic aqueous media: adlayer structural inferences from infrared spectroscopy and scanning tunneling microscope. J. Electroanal. Chem. 1994, 375, 357-366.

(12) Ataka, K.-I.; Osawa, M. In Situ Infrared Study of Water-Sulfate Coadsorption on Gold(111) in Sulfuric Acid. Langmuir 1998, 14, 951-959.

(13) Shingaya, Y.; Ito, M. Comparison of a bisulfate anion adsorbed on $\mathrm{M}(111)(\mathrm{M}=\mathrm{Pt}, \mathrm{Rh}, \mathrm{Au}, \mathrm{Ag}$ and $\mathrm{Cu})$. J. Electroanal. Chem. 1999, 467, 299-306.

(14) Nakamura, M.; Shingaya, Y.; Ito, M. Hydration processes on metal surfaces studied by IR and STM: a model for the potential drop across the electric double layers. Surf. Sci. 2002, 502-503, 474-484.

(15) Cuesta, A.; Kleinert, M.; Kolb, D. M. The adsorption of sulfate and phosphate on $\mathrm{Au}(111)$ and $\mathrm{Au}(100)$ electrodes: an in situ STM study. Phys. Chem. Chem. Phys. 2000, 2, 5684-5690.

(16) Shi, Z.; Lipkowski, J.; Gamboa, M.; Zelenay, P.; Wieckowski, A. Investigations of $\mathrm{SO}_{4}{ }^{2-}$ adsorption at the $\mathrm{Au}(111)$ electrode by chronocoulometry and radiochemistry. J. Electroanal. Chem. 1994, 366, 317-326.

(17) Venkatachalam, S.; Jacob, T. DFT Studies on the Nature of Coadsorbates on $\mathrm{SO}_{4}{ }^{2-} / \mathrm{Au}(111)$. Z. Phys. Chem. 2007, 221, 13931406.

(18) Funtikov, A. M.; Stimming, U.; Vogel, R. Anion adsorption from sulfuric acid solutions on $\operatorname{Pt}(111)$ single crystal electrodes. $J$. Electroanal. Chem. 1997, 428, 147-153.

(19) Wan, L. J.; Yau, S.-L.; Itaya, K. Atomic Structure of Adsorbed Sulfate on $\mathrm{Rh}(111)$ in Sulfuric Acid Solution. J. Phys. Chem. 1995, 99, 9507-9513.

(20) Li, W.-H.; Nichols, R. J. An in situ STM study of sulphate adsorption on copper(111) in acidic aqueous electrolytes. $J$. Electroanal. Chem. 1998, 456, 153-160.

(21) Wan, L.-J.; Hara, M.; Inukai, J.; Itaya, K. In Situ Scanning Tunneling Microscopy of Well-Defined $\operatorname{Ir}(111)$ Surface: HighResolution Imaging of Adsorbed Sulfate. J. Phys. Chem. B 1999, 103, 6978-6983.

(22) Wan, L.-J.; Suzuki, T.; Sashikata, K.; Okada, J.; Inukai, J.; Itaya, K. In situ scanning tunneling microscopy of adsorbed sulfate on well-defined $\operatorname{Pd}(111)$ in sulfuric acid solution. J. Electroanal. Chem. 2000, 484, 189-193.

(23) Shingaya, Y.; Ito, M. Model double layer structures on $\mathrm{M}(111)(\mathrm{M}=\mathrm{Pt}, \mathrm{Rh}, \mathrm{Au}, \mathrm{Cu}$ and $\mathrm{Ag})$ in a sulfuric acid solution. Electrochim. Acta 1998, 44, 745-751.

(24) Kolics, A.; Wieckowski, A. Adsorption of Bisulfate and Sulfate Anions on a Pt(111). J. Phys. Chem. B 2001, 105, 2588-2595.

(25) Jinnouchi, R.; Hatanaka, T.; Morimoto, Y.; Osawa, M. First principles study of sulfuric acid anion adsorption on a Pt (111) electrode. Phys. Chem. Chem. Phys. 2012, 14, 3208-3218.

(26) Tian, Z.-Q.; Ren, B.; Wu, D.-Y. Surface-Enhanced Raman Scattering: From Noble to Transition Metals and from Rough Surfaces to Ordered Nanostructures. J. Phys. Chem. B 2002, 106, 9463-9483. 
(27) Liu, X.; Wang, D.; Wan, L. Progress of electrode/electrolyte interfacial investigation of $\mathrm{Li}$-ion batteries via in situ scanning probe microscopy. Science Bulletin 2015, 60, 839-849.

(28) Wang, H.; Zhou, Y.-W.; Cai, W.-B. Recent applications of in situ ATR-IR spectroscopy in interfacial electrochemistry. Current Opinion in Electrochemistry 2017, 1, 73-79.

(29) Koper, M. T. Fuel Cell Catalysis: A Surface Science Approach. John Wiley \& Sons, Inc.: Hoboken, New Jersey, 2009.

(30) Li, J. F.; Huang, Y. F.; Ding, Y.; Yang, Z. L.; Li, S. B.; Zhou, X. S.; Fan, F. R.; Zhang, W.; Zhou, Z. Y.; Wu, D. Y.; Ren, B.; Wang, Z. L.; Tian, Z. Q. Shell-isolated nanoparticle-enhanced Raman spectroscopy. Nature 2010, 464, 392-395.

(31) Li, J. F.; Ding, S. Y.; Yang, Z. L.; Bai, M. L.; Anema, J. R.; Wang, X.; Wang, A.; Wu, D. Y.; Ren, B.; Hou, S. M.; Wandlowski, T.; Tian, Z. Q. Extraordinary enhancement of Raman scattering from pyridine on single crystal $\mathrm{Au}$ and $\mathrm{Pt}$ electrodes by shell-isolated $\mathrm{Au}$ nanoparticles. J. Am. Chem. Soc. 2011, 133, 15922-15925.

(32) Honesty, N. R.; Gewirth, A. A. Shell-isolated nanoparticle enhanced Raman spectroscopy (SHINERS) investigation of benzotriazole film formation on $\mathrm{Cu}(100), \mathrm{Cu}(111)$, and $\mathrm{Cu}$ (poly). $J$. Raman Spectrosc. 2012, 43, 46-50.

(33) Li, C. Y.; Le, J. B.; Wang, Y. H.; Chen, S.; Yang, Z. L.; Li, J. F.; Cheng, J.; Tian, Z. Q. In situ probing electrified interfacial water structures at atomically flat surfaces. Nat. Mater. 2019, 18, 697-701.

(34) Fang, Y.; Dong, J.-C.; Ding, S.-Y.; Cheng, J.; Feliu, J. M.; Li, J.-F.; Tian, Z.-Q. Toward a quantitative theoretical method for infrared and Raman spectroscopic studies on single-crystal electrode/liquid interfaces. Chem. Sci. 2020, 11, 1425-1430.

(35) Clavilier, J.; Faure, R.; Guinet, G.; Durand, R. Preparation of monocrystalline Pt microelectrodes and electrochemical study of the plane surfaces cut in the direction of the $\{111\}$ and $\{110\}$ planes. $J$. Electroanal. Chem. 1980, 107, 205-209.
(36) Kresse, G.; Furthmuller, J. Efficient iterative schemes for ab initio total-energy calculations using a plane-wave basis set. Phys. Rev. B 1996, 54, 11169-11186.

(37) Kresse, G.; Joubert, D. From ultrasoft pseudopotentials to the projector augmented-wave method. Phys. Rev. B 1999, 59, 17581775.

(38) Hammer, B.; Hansen, L. B.; Nørskov, J. K. Improved adsorption energetics within density-functional theory using revised Perdew-Burke-Ernzerhof functionals. Phys. Rev. B 1999, 59, 74137421.

(39) Tersoff, J.; Hamann, D. R. Theory of the scanning tunneling microscope. Phys. Rev. B 1985, 31, 805-813.

(40) Mathew, K.; Kolluru, V. S. C.; Mula, S.; Steinmann, S. N.; Hennig, R. G. Implicit self-consistent electrolyte model in plane-wave density-functional theory. J. Chem. Phys. 2019, 151, 234101.

(41) Sato, K.; Yoshimoto, S.; Inukai, J.; Itaya, K. Effect of sulfuric acid concentration on the structure of sulfate adlayer on $\mathrm{Au}(111)$ electrode. Electrochem. Commun. 2006, 8, 725-730.

(42) Suto, K.; Magnussen, O. M. In situ Video-STM studies of sulfate dynamics on Au(111). J. Electroanal. Chem. 2010, 649, 136141.

(43) Garcia-Araez, N.; Rodriguez, P.; Navarro, V.; Bakker, H. J.; Koper, M. T. M. Structural Effects on Water Adsorption on Gold Electrodes. J. Phys. Chem. C 2011, 115, 21249-21257.

(44) Simeone, F. C.; Kolb, D. M.; Venkatachalam, S.; Jacob, T. The $\mathrm{Au}(111) /$ electrolyte interface: a tunnel-spectroscopic and DFT investigation. Angew. Chem. Int. Ed. 2007, 46, 8903-8906.

(45) Ataka, K.-I.; Yotsuyanagi, T.; Osawa, M. PotentialDependent Reorientation of Water Molecules at an Electrode/Electrolyte Interface Studied by Surface-Enhanced Infrared Absorption Spectroscopy. J. Phys. Chem. 1996, 100, 10664-10672. 


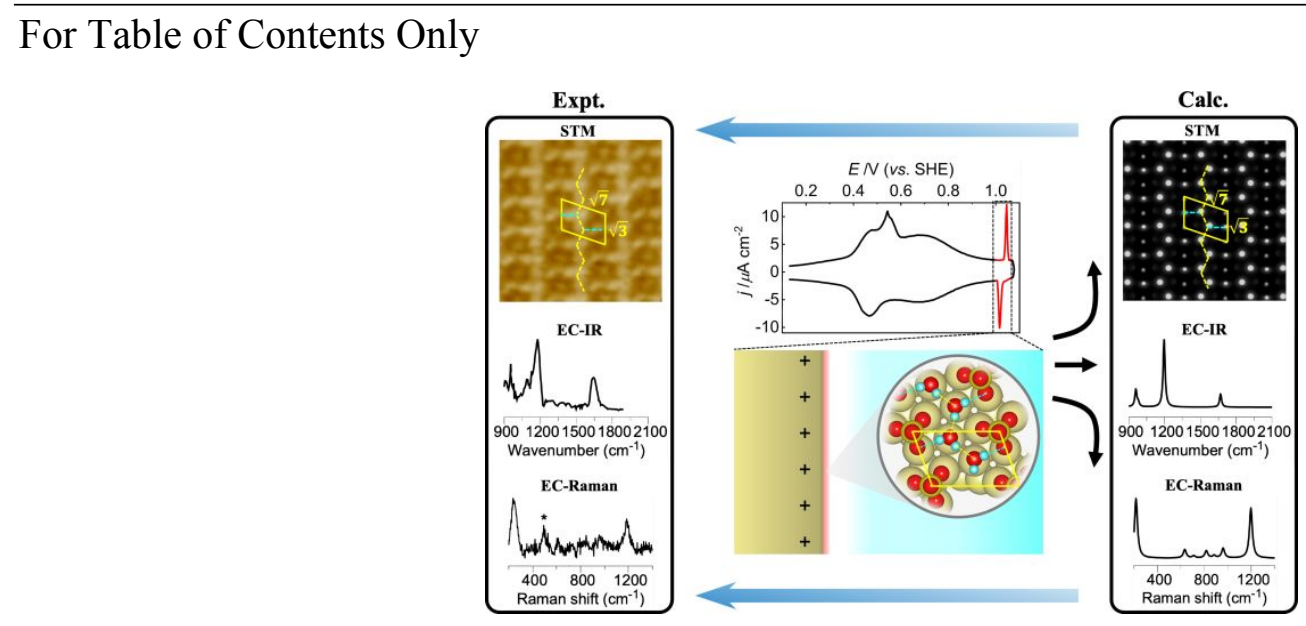

The adstructure with the $(\sqrt{3} \times \sqrt{ } 7)$ symmetry at the interface of $\mathrm{Au}(111)$ electrode-sulfuric acid solution was revealed by combining high-resolution electrochemical scanning tuning microscopy, electrochemical Raman spectroscopy, and especially, the newly-developed computational method on electrochemical infrared and Raman spectroscopies. 


\section{(B)}

$$
\text { (A) }
$$

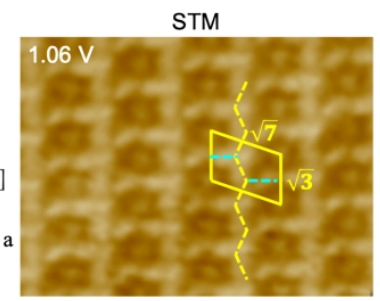

(D)
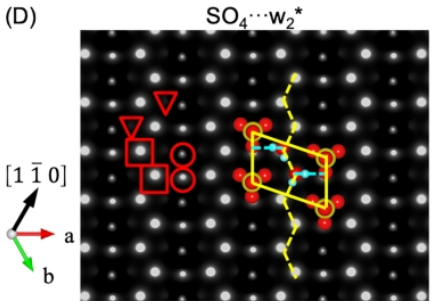

(C)

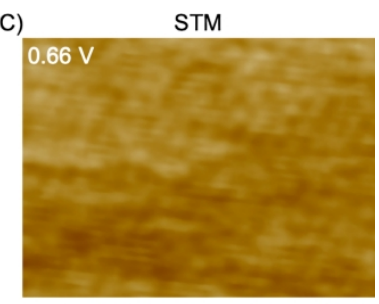

(E)
Charge density

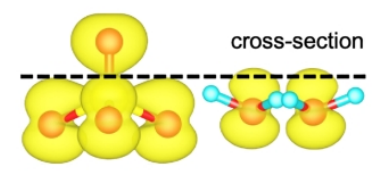

Figure 1. Probing atomistic structures in the $\mathrm{Au}(111) / \mathrm{H}_{2} \mathrm{SO}_{4}$ solution interface. (A) Cyclic voltammetry curve of $\mathrm{Au}(111)$ in $0.1 \mathrm{M} \mathrm{H}_{2} \mathrm{SO}_{4}$ aqueous solution, scan rate: $20 \mathrm{mV} / \mathrm{s}$. (B) and (C) High resolution STM image at $1.06 \mathrm{~V}$ and $0.66 \mathrm{~V}$ vs. SHE, respectively. (D) Calculated STM image of the $A u(111)(\sqrt{ } 3 \times \sqrt{ } 7)-$ $\left(\mathrm{SO}_{4} \cdots \mathrm{w}_{2}\right)$ configuration. (E) Distribution of charge density of the $\mathrm{SO}_{4} \cdots \mathrm{w}_{2} *$ configuration near the Fermi level $E_{\mathrm{F}}$. The unit vectors $\boldsymbol{a}, \boldsymbol{b}$ are the basic vectors of the $\mathrm{Au}(111)(1 \times 1)$ along with the $\left[\begin{array}{lll}1 & 0 & -1\end{array}\right]$ and $[01-$ $1]$ directions, respectively. The basic vectors of $A u(111)(\sqrt{ } 3 \times \sqrt{ } 7)$ are defined as $2 \boldsymbol{b}-\boldsymbol{a}(\sqrt{3}$ direction) and $2 \boldsymbol{a}+\boldsymbol{b}(\sqrt{ } 7$ direction), respectively. The main maxima, secondary maxima and minima spots correspond to red panes, circle and triangle frames, respectively.

$220 \times 101 \mathrm{~mm}(300 \times 300 \mathrm{DPI})$ 
(A) O1-Au1 O3-Au3(B)
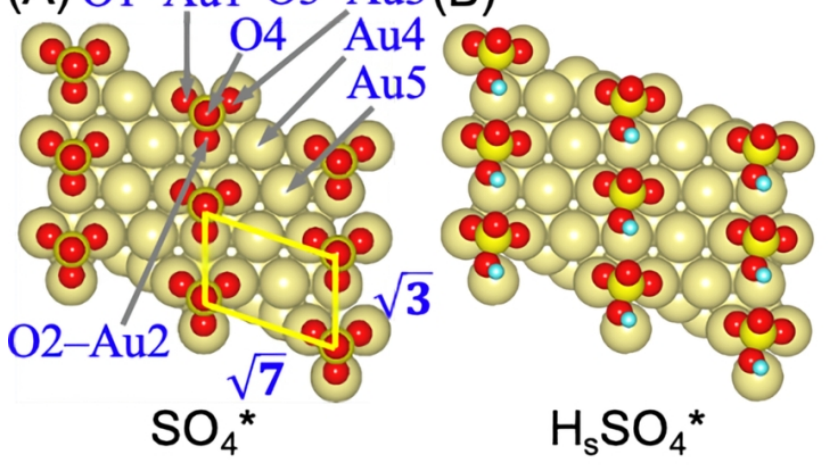

(C)

(D)

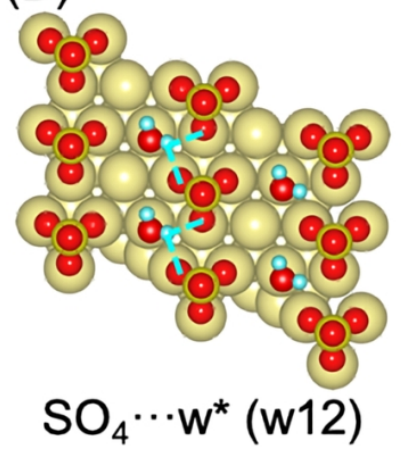

(G)

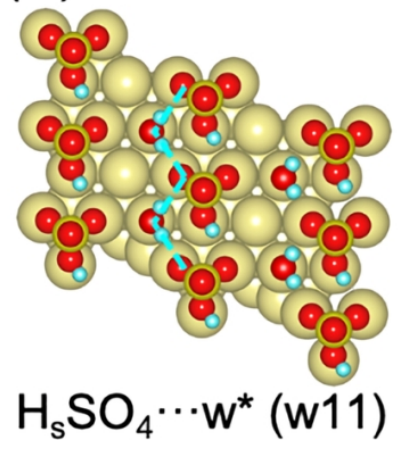

(E)

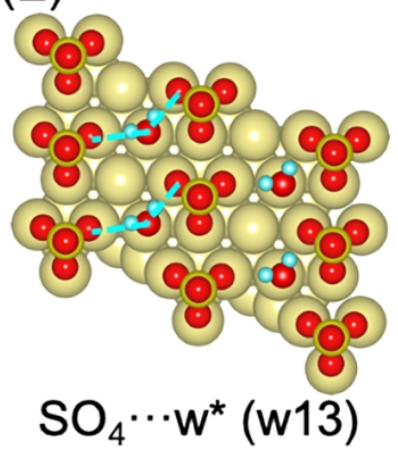

$(\mathrm{H})$

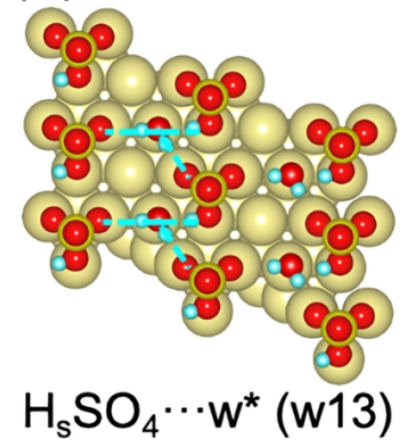

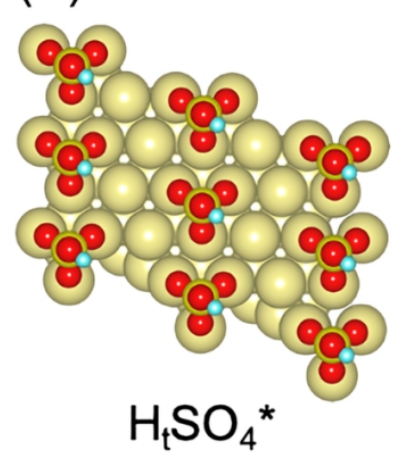

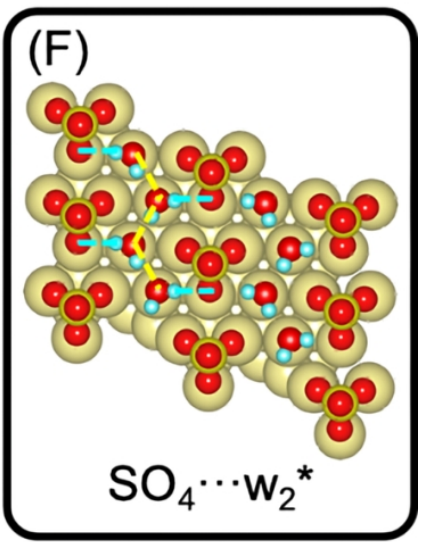

(I)

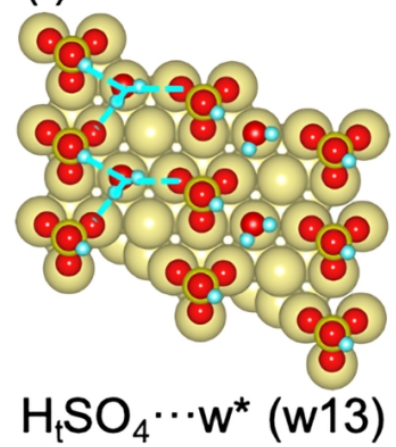

Figure 2. Nine proposed $\mathrm{Au}(111)(\sqrt{ } 3 \times \sqrt{ } 7)-X$ configurations with different adsorbates $\mathrm{X}$. (A) $\mathrm{SO}_{4} *$; $(\mathrm{B})$ and (C) $\mathrm{H}_{\mathrm{S}} \mathrm{SO}_{4} *$ and $\mathrm{H}_{\mathrm{t}} \mathrm{SO}_{4} *$ with $\mathrm{H}$ bonding with $\mathrm{O} 2$ and $\mathrm{O} 4$, respectively; (D) and (E) $\mathrm{SO}_{4} \cdots \mathrm{w}^{*}$ (w12) and $\mathrm{SO}_{4} \cdots \mathrm{w}^{*}$ (w13) consist of a sulfate anion and a co-adsorbed water molecule with $\mathrm{SO}_{4} \cdots \mathrm{w}^{*}$ hydrogen-bonds through $\mathrm{O} 1$ and $\mathrm{O} 2$ or $\mathrm{O} 1$ and $\mathrm{O} 3$, respectively; (F) $\mathrm{SO}_{4} \cdots \mathrm{w}_{2} *$ consists of a sulfate anion and a co-adsorbed dual-water ( $\mathrm{w}_{2}$ ) molecules; (G) and $(\mathrm{H}) \mathrm{H}_{5} \mathrm{SO}_{4} \cdots \mathrm{w}^{*}$ (w11) and $\mathrm{H}_{5} \mathrm{SO}_{4} \cdots \mathrm{w}^{*}$ (w13) consist of a bisulfate anion with $\mathrm{H}$ bonding with $\mathrm{O} 2$ and a co-adsorbed water molecule with $\mathrm{H}_{5} \mathrm{SO}_{4} \cdots \mathrm{w}^{*}$ hydrogen-bonds through $\mathrm{O} 1$ and $\mathrm{O} 1$ or $\mathrm{O} 1$ and $\mathrm{O} 3$ from different $\mathrm{H}_{5} \mathrm{SO}_{4} *$ molecules; (I) $\mathrm{H}_{\mathrm{t}} \mathrm{SO}_{4} \cdots \mathrm{w} *(\mathrm{w} 13)$ consists of a bisulfate anion with $\mathrm{H}$ bonding with $\mathrm{O} 4$ and a co-adsorbed water molecule with $\mathrm{H}_{\mathrm{t}} \mathrm{SO}_{4} \cdots \mathrm{w}^{*}$ hydrogen-bonds through $\mathrm{O} 1$ and $\mathrm{O} 3$ from different $\mathrm{H}_{\mathrm{t}} \mathrm{SO}_{4} *$ molecules. The golden, yellow, red, and cyan balls denote $\mathrm{Au}, \mathrm{S}, \mathrm{O}$, and $\mathrm{H}$ atoms, respectively. The dashed cyan and yellow lines denote (bi)sulfate-water hydrogen bonds and water-water hydrogen bonds, respectively. 

$110 \times 137 \mathrm{~mm}(300 \times 300 \mathrm{DPI})$ 
(A)

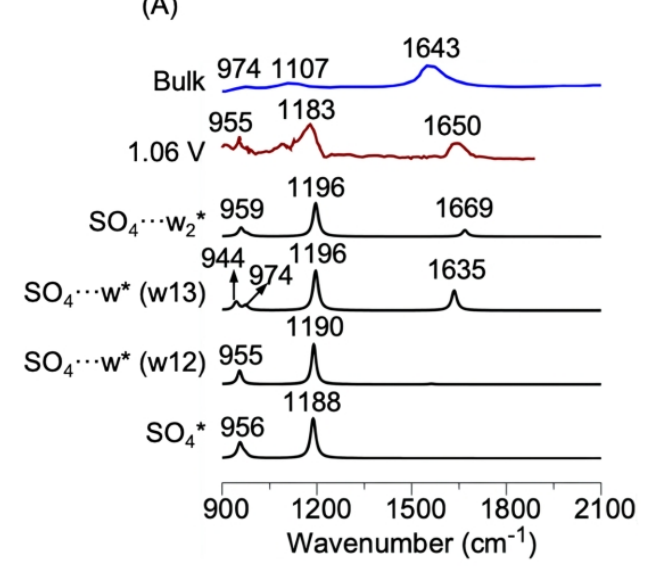

IR

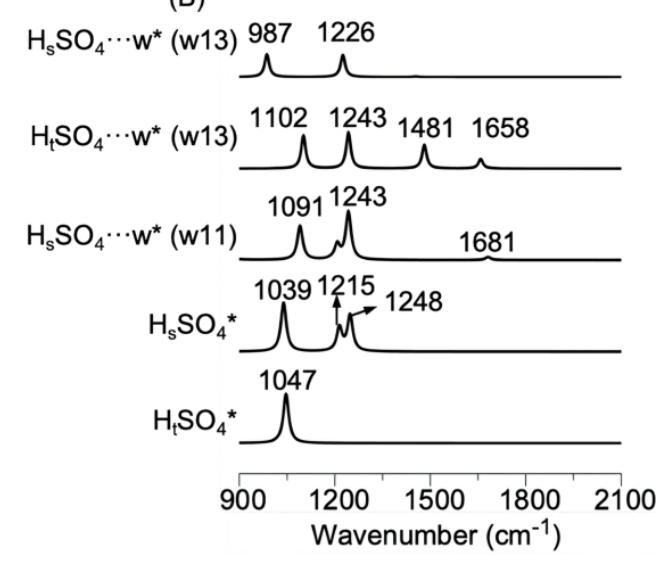

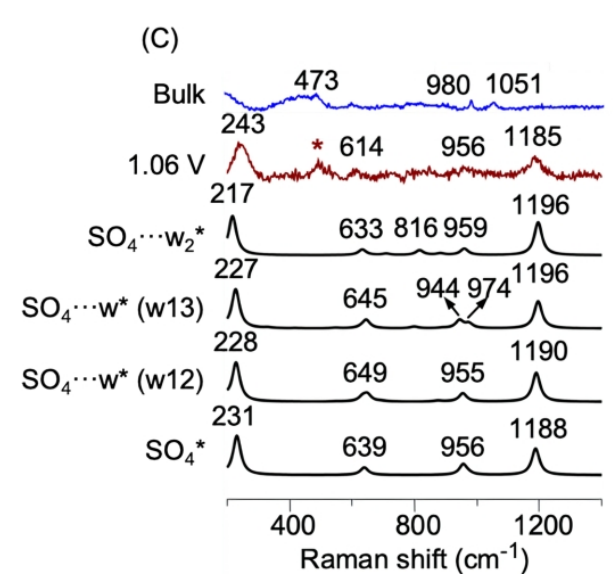

Raman

(D) 238

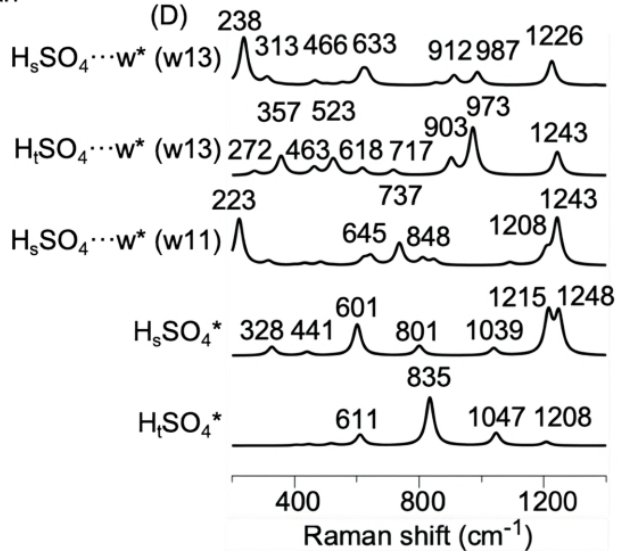

Figure 3. Calculated EC-IR and -Raman spectra of the $A u(111)(\sqrt{ } 3 \times \sqrt{ } 7)-X$ configurations at $1.06 \mathrm{~V}$ vs. SHE. EC-IR spectra of the configurations containing sulfate anions in ( $A$ ) or bisulfate anions in (B). EC-Raman spectra of the configurations containing sulfate anions in (C) or bisulfate anions in (D). The blue curves in panel $A$ and $C$, respectively, denote the measured IR and Raman spectrum of bulk solution. The dark red curves in panel A and C, respectively, denote the measured EC-IR and -Raman spectrum at $1.06 \mathrm{~V}$. The measured IR spectra were adapted from ref. 12 with permission, copyright (1998) American Chemical Society. 


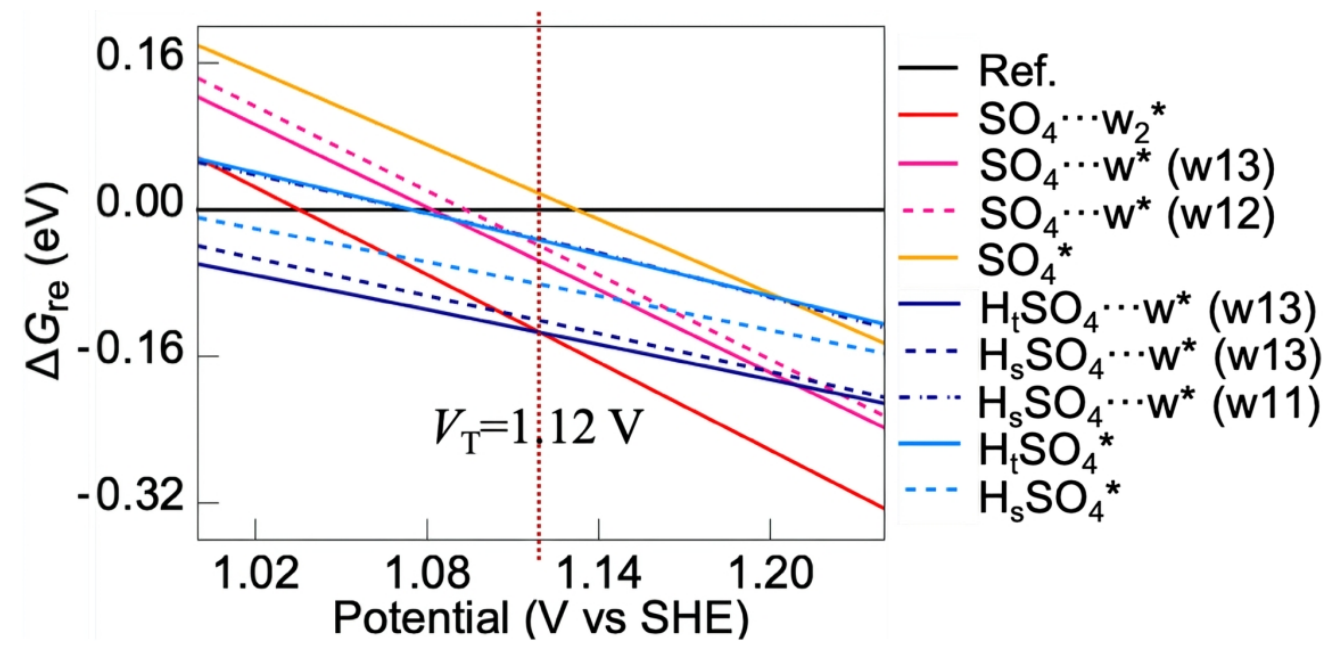

Figure 4. Potential-dependent reaction free energy diagram from $1.00 \mathrm{~V}$ to $1.24 \mathrm{~V} v \mathrm{vs}$. SHE. The black line denotes the reference state $\left(\mathrm{HSO}_{4}{ }^{-}(\mathrm{aq})+2 \mathrm{H}_{2} \mathrm{O}(\mathrm{aq})+{ }^{*}\right)$. The solid and dashed parabolas denote $\mathrm{X}=$ $\mathrm{H}_{\mathrm{t}} \mathrm{SO}_{4} *$ and $\mathrm{H}_{\mathrm{S}} \mathrm{SO}_{4} *$ in blue, $\mathrm{SO}_{4} \cdots \mathrm{w}^{*}$ (w13) and (w12) in pink, $\mathrm{H}_{\mathrm{t}} \mathrm{SO}_{4} \cdots \mathrm{w}^{*}$ (w13) and $\mathrm{H}_{\mathrm{S}} \mathrm{SO}_{4} \cdots \mathrm{w}^{*}$ (w13) in dark blue.

$165 \times 80 \mathrm{~mm}(300 \times 300 \mathrm{DPI})$ 
Expt.

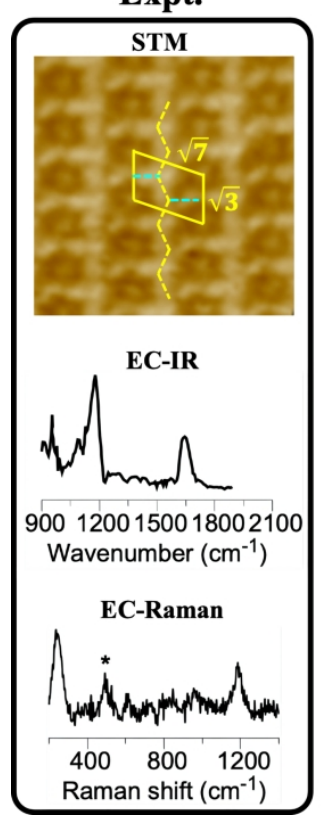

Calc.

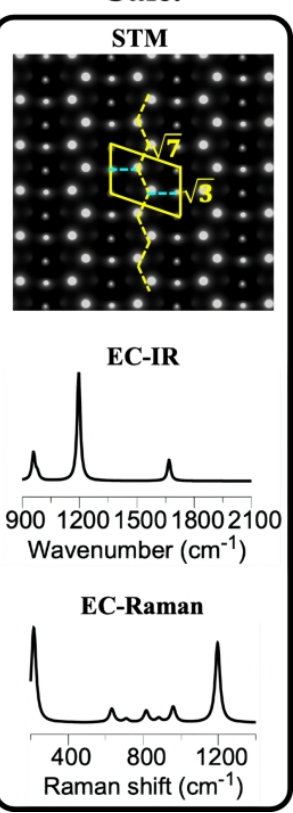

The adstructure with the $(\sqrt{ } 3 \times \sqrt{ } 7)$ symmetry at the interface of $A u(111)$ electrode-sulfuric acid solution was revealed by combining high-resolution electrochemical scanning tuning microscopy, electrochemical Raman spectroscopy, and especially, the newly-developed computational method on electrochemical infrared and Raman spectroscopies.

$249 \times 160 \mathrm{~mm}(300 \times 300$ DPI $)$ 